\title{
Estudo da alteração intempérica atuante em escultura de Jesus Cristo do século XIX e seu suporte, pertencentes ao Mosteiro de São Bento, Rio de Janeiro, RJ
} Study of the weathering alterations in a $19^{\text {th }}$ century sculpture of Jesus Christ and its support, belonging to the Monastery of São Bento, Rio de Janeiro, RJ

\author{
Carla Corrêa Felix ${ }^{1}$ (D), Kátia Leite Mansur ${ }^{1}$ (D), Roberto Carlos da Conceição Ribeiro² (]) \\ ${ }^{1}$ Universidade Federal do Rio de Janeiro - UFRJ, Departamento de Geologia, Programa de Pós-Graduação em Geologia, Avenida Athos \\ da Silveira Ramos, 274, CEP 21941-916, Cidade Universitária, Rio de Janeiro, RJ, BR (carlacfelix8@gmail.com; katia@geologia.ufrj.br) \\ ${ }^{2}$ Centro de Tecnologia Mineral - CETEM, Rio de Janeiro, RJ, BR (rcarlos@cetem.gov.br)
}

Recebido em 23 de novembro de 2020; aceito em 16 de agosto de 2021.

\begin{abstract}
Resumo
O Mosteiro de São Bento do Rio de Janeiro apresenta exposto, em seu jardim, uma escultura do busto de Jesus Cristo sobre um suporte do século XIX. Ambas as peças são afetadas pelo intemperismo e se alteraram. Foram realizados caracterização tecnológica das peças e ensaios que forneceram dados que auxiliaram no entendimento das causas dessas alterações. Foram executadas análises por fluorescência de raios X (FRX), difração de raios X (DRX), ensaio colorimétrico, determinação da absorção de água (tubo de Karsten), velocidade ultrassônica e avaliação da dureza. As peças foram higienizadas para avaliação de poluentes e do $\mathrm{pH}$. Os resultados de DRX indicaram que a escultura é composta de mármore (predominância de calcita) e do suporte de alabastro. Os resultados de FRX corroboraram com os de DRX, apontando que a escultura é composta de 49,90\% de óxido de cálcio e 44,30\% de perda ao fogo, associada à presença de carbonatos, enquanto o suporte apresenta 30,90\% de óxido de cálcio, $21,90 \%$ de óxido de enxofre e $22,00 \%$ de perda ao fogo. No ensaio colorimétrico, a escultura apresentou cor cinza-escura, enquanto mármores semelhantes sãos, utilizados para comparação, tendem a cinza-claro e branco. No ensaio de absorção de água, ambas as peças apresentaram baixa permeabilidade. O ensaio de dureza indicou médias de valores maiores na estátua (489,07; 411,20 e 452,19 HLD) do que no suporte (188,14; 172,28; 164,57 e 201,71 HLD), indicando que o mármore é mais resistente do que o alabastro. Os resultados permitiram identificar que as alterações se devem, principalmente, ao local onde a escultura está exposta, e foi possível propor medidas para auxiliar na conservação desses objetos históricos.
\end{abstract}

Palavras-chave: Mármore; Alabastro; Alterabilidade de rocha; Mosteiro de São Bento do Rio de Janeiro; Caracterização tecnológica de rochas.

\begin{abstract}
The Monastery of São Bento in Rio de Janeiro has a sculpture of the bust of Jesus Christ on a support from the $19^{\text {th }}$ century on display. Both pieces are affected by weathering and have been degraded. A technological characterization of the pieces and some tests were carried out, which provided data that helped to understand the causes of these alterations. X-ray fluorescence (XRF), X-ray diffraction (XRD), colorimetric test, determination of water absorption (Karsten tube), P-wave velocity, and hardness evaluation were performed. The parts were washed for evaluation of pollutants and $\mathrm{pH}$. The results of the XRD indicated that the sculpture is composed of marble (mainly calcite) and the support of alabaster. The results of XRF corroborated with those of XRD, pointing out that the sculpture is composed of $49.90 \%$ calcium oxide and $44.30 \%$ loss on ignition, associated with the presence of carbonates, while the support contains $30.90 \%$ calcium oxide, $21.90 \%$ sulfur oxide, and $22.00 \%$ loss on ignition. In the colorimetric test, the sculpture was classified as dark grey, while similar unweathered marbles, used for comparison, tend to light grey and white. In the water absorption test, both pieces showed low permeability. The hardness test indicated higher mean values for the statue (489.07; 411.20; and 452.19 HLD) than for the support $(188.14 ; 172.28 ; 164.57$; and 201.71 HLD), indicating that marble is more resistant than alabaster. The results made it possible to identify that the changes are mainly due to where the sculpture is placed, thus allowing us to propose measures to aid in the conservation of historical objects.
\end{abstract}

Keywords: Marble; Alabaster; Alterability of rocks; Monastery of São Bento in Rio de Janeiro; Technological characterization of rocks. 


\section{INTRODUÇÃO}

Rochas ornamentais, pedras naturais, materiais lapídeos, rochas dimensionadas ou rochas de cantaria são materiais rochosos extraídos e beneficiados a fim de serem utilizados com funções de revestimento, decoração ou estrutura. A utilização das rochas ornamentais acompanhou a evolução da humanidade e, graças a sua durabilidade, consistem em um registro dessa evolução, da cultura e dos costumes ao longo da história (Vidal et al., 2013).

De acordo com Özturk (1992), a partir do momento em que os monumentos pétreos são expostos ao ar livre, processos de degradação natural, como o intemperismo, atuam sobre as rochas que os compõem. Dessa forma, elas se alteram e se degradam, colocando em risco a preservação dos monumentos. Essa degradação inclui mudanças físicas e químicas, que resultam na diminuição da resistência mecânica da rocha e em modificações na aparência estética, desde alterações cromáticas até esfoliações de camadas superficiais (Frascá e Yamamoto, 2014). A exposição às condições atmosféricas, incluindo a poluição do ar, resulta no processo de envelhecimento da pedra (Winkler, 2013).
Nesse contexto, está incluído o Mosteiro de São Bento do Rio de Janeiro, localizado no centro da cidade do Rio de Janeiro, fundado em 1586 e tombado como patrimônio nacional pelo Instituto do Patrimônio Histórico e Artístico Nacional (IPHAN) no ano de 1938 (IPHAN, 2019a, 2019b). Uma escultura do busto de Jesus Cristo colocado sobre um suporte estava exposta em um dos jardins do claustro (Jardim de Jericó), e observou-se que ambos estavam em processo de alteração e degradação. São eles os objetos de estudo do presente trabalho (Figura 1). Neste artigo, ambos os termos, "degradação" e "alteração", serão usados como sinônimos, significando qualquer modificação física ou química das rochas.

Segundo o International Council on Monuments and Sites - ICOMOS (1964), de acordo com a Carta de Veneza, os monumentos testemunham nos dias atuais as tradições de diversas gerações passadas, caracterizando sua importância. Segundo o Art. $3^{\circ}$, seu restauro e sua conservação visam salvaguardar tanto a obra de arte quanto o testemunho histórico.

$\mathrm{O}$ conhecimento dos mecanismos que promovem tais deteriorações é essencial para propiciar ações adequadas de conservação e restauração das rochas ornamentais (Ribeiro et al., 2018). Da mesma forma, a caracterização das rochas
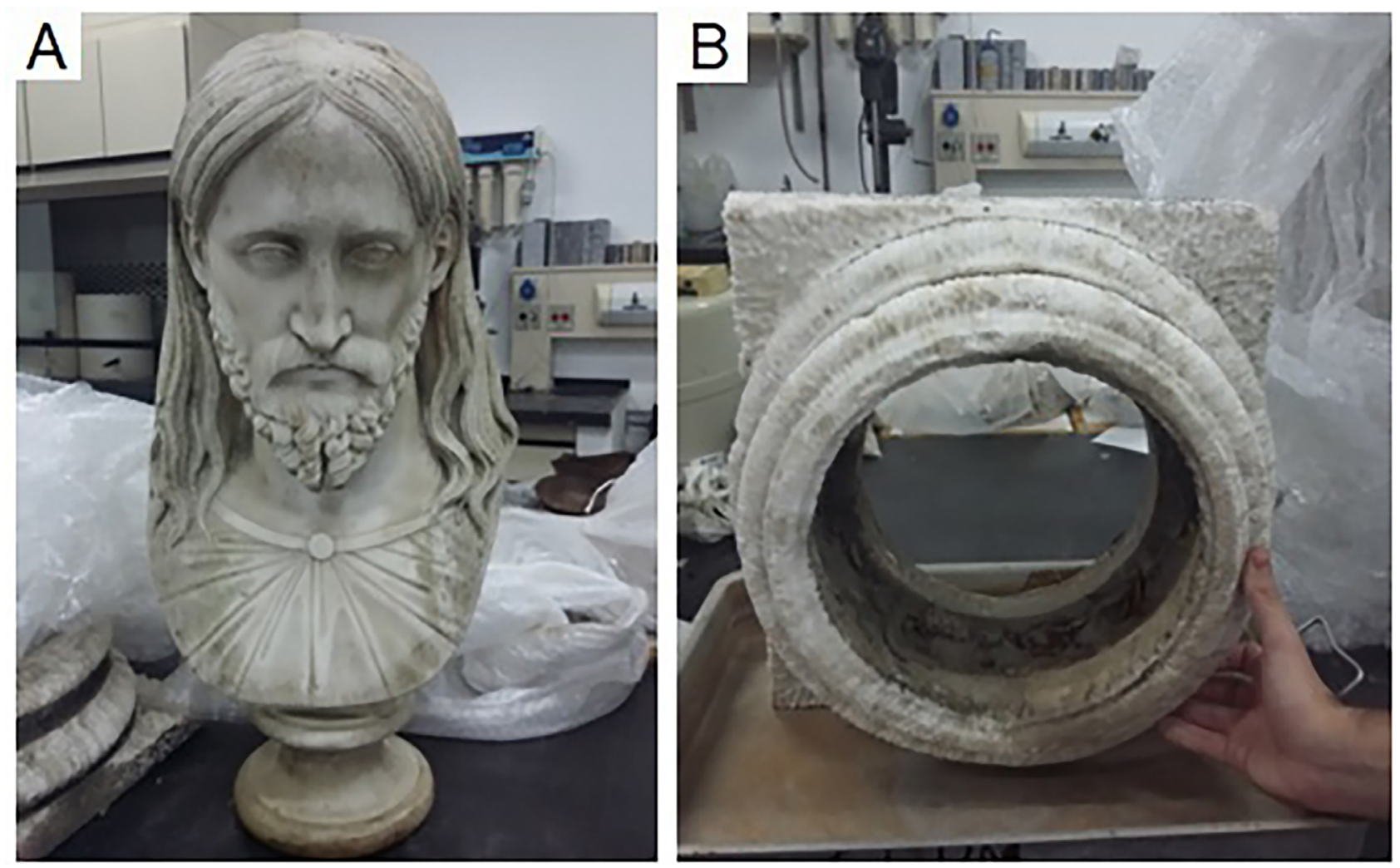

Figura 1. (A) Escultura do busto de Jesus; (B) suporte que tem a função de encaixe da escultura. Ambos os objetos apresentam alterações intempéricas por ficarem localizados ao ar livre no Jardim de Jericó, Mosteiro de São Bento, Rio de Janeiro. 
ornamentais e das causas das alterações será fundamental para a indicação dos métodos a serem aplicados para conter a degradação do monumento (Bakolas et al., 1998).

Em se tratando de obras de arte pertencentes a um bem tombado, não podem ser alteradas. Portanto, foram aplicados métodos não destrutivos para caracterizar as rochas ornamentais e avaliar as alterações.

\section{Autoria e origem da escultura}

A escultura está assinada por "F. Pettrich" no ano de 1843 (Figura 2). Para levantar informações sobre a autoria da escultura, foi realizada uma entrevista com o Monge Pascoal, do Mosteiro de São Bento do Rio de Janeiro, e posteriormente foi executada uma pesquisa on-line a respeito do escultor. De acordo com o Monge Pascoal, as doações de obras para o Mosteiro de São Bento só passaram a ser documentadas a partir de 1900, não existindo registros anteriores a esse ano. Considerando a data da assinatura e a ausência de documentação sobre a obra, pôde-se inferir que foi incorporada ao mosteiro antes do ano de 1900.

Segundo o site de artes The Victorian Artists (1997), Ferdinand August Pettrich foi um escultor nascido na Alemanha que já atuou em diferentes países, como Estados Unidos, Brasil e Itália, onde faleceu em 1872. Ferdinand teria chegado ao Rio de Janeiro entre o ano de 1842 e 1843 , servindo à corte imperial como escultor de Dom Pedro II. De acordo com Auler (1963), Ferdinand Pettrich atuou no Rio de Janeiro e, possivelmente, foi o primeiro a esculpir em mármore no Brasil. Sua primeira aparição no país foi em uma exposição na Academia Imperial das Belas Artes, no Rio de Janeiro, em 1843, com algumas produções, entre elas uma cabeça de Jesus Cristo que, possivelmente, é a escultura estudada.

\section{MATERIAIS E MÉTODOS}

Primeiramente, foram realizados mapeamento de danos e pesquisa sobre a autoria da escultura. Os ensaios

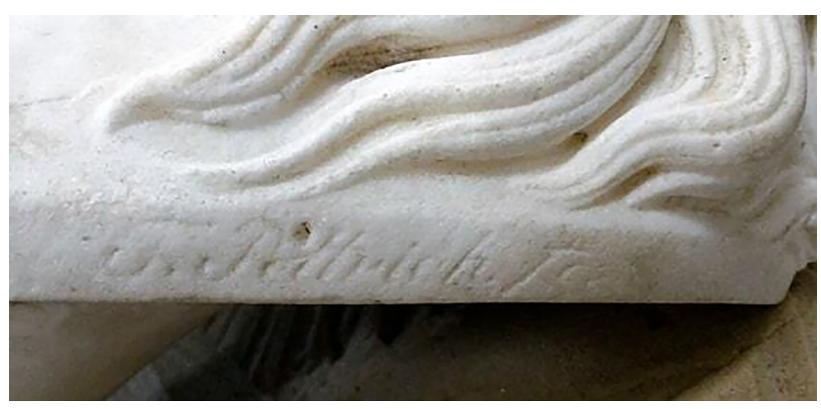

Figura 2. Imagem da assinatura de F. Pettrich na lateral da escultura de Jesus Cristo. realizados neste estudo envolveram caracterização tecnológica das rochas, análises químicas e análises físicas, de forma a identificar a mineralogia e a química da rocha, bem como os agentes intempéricos atuantes e o grau de alteração sofrido.

Como não há certeza a respeito da origem do mármore que compõe a escultura do busto de Jesus, duas amostras, com dimensões de aproximadamente $7 \times 4 \mathrm{~cm}$ cada, de mármores sãos, com características químicas e mineralógicas similares, denominados Mármore Brasileiro (MB) e Mármore Carrara (MC) (Figura 3), foram submetidas a alguns ensaios para fins comparativos no resultado. O MB utilizado tem procedência do município de Cachoeiro de Itapemirim, no Espírito Santo.

\section{Mapeamento de danos}

As morfologias de alteração presentes tanto na escultura do busto quanto no suporte foram identificadas de acordo com observações visuais fotográficas e classificadas com base no glossário ICOMOS (2008).

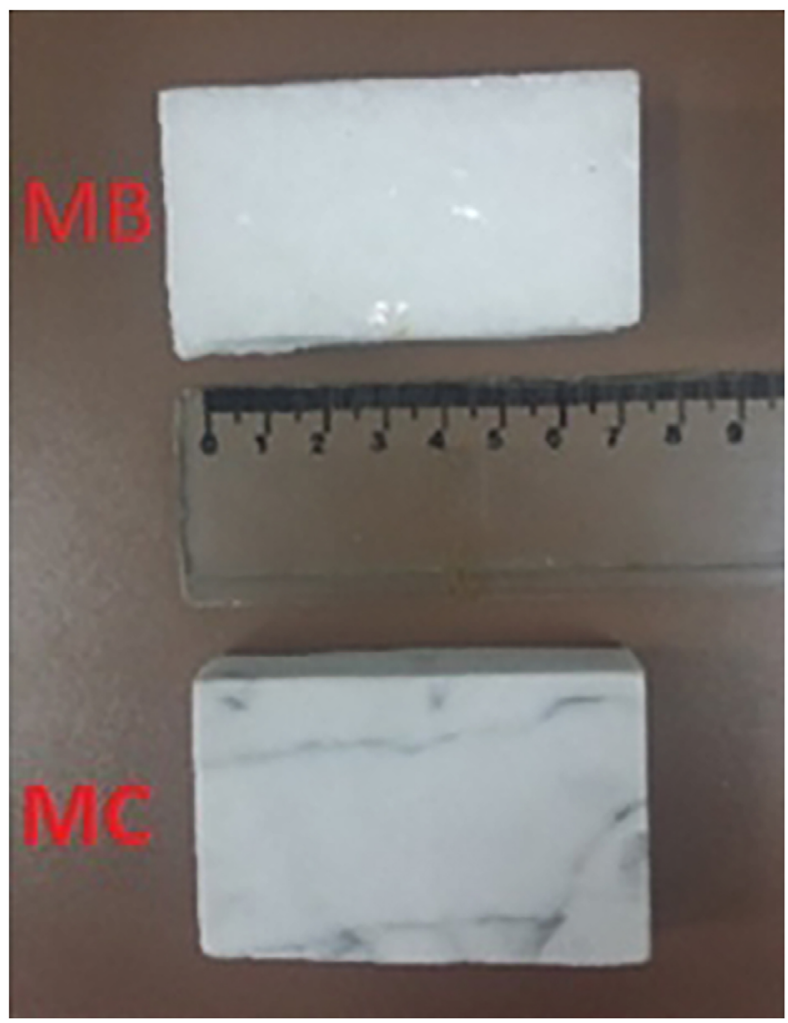

MB: Mármore Brasileiro; MC: Mármore Carrara.

Figura 3. Amostras sãs de Mármore Brasileiro e Mármore Carrara utilizadas com finalidade de comparação aos resultados obtidos dos ensaios com o mármore da escultura de Jesus. 


\section{Fluorescência de raios $\mathrm{X}$ : caracterização química}

Neste estudo, foi realizado o ensaio de fluorescência de raios X - FRX (caracterização química das rochas) na Coordenação de Análises Químicas e Mineralógicas (COAMI) do Centro de Tecnologia Mineral (CETEM), no qual foram necessários $0,4 \mathrm{~g}$ de amostra, que foi retirada com espátula, por raspagem, da parte de baixo da escultura. A amostra foi preparada por fusão a $1.050^{\circ} \mathrm{C} \mathrm{em}$ uma máquina de fusão do modelo $V U L C A N$ e o fundente utilizado foi o tetraborato de lítio.

Já o preparo da amostra do suporte foi realizado por meio de uma prensa automática da marca FLUXANA, modelo VANEOX. As pastilhas obtidas foram analisadas em espectrômetro por FRX PANALYTICAL, modelo AXIOS MAX, equipado com tubo de $\mathrm{Rh}$.

\section{Difração de raios X: caracterização mineralógica}

Para o ensaio de difração de raios X — DRX (caracterização mineralógica das rochas), foram utilizados aproximadamente $3,0 \mathrm{~g}$ de amostra tanto do busto quanto do suporte, que foi retirada com espátula, por raspagem, da parte de baixo da escultura. Para a realização do procedimento, foi utilizado o difratômetro modelo D4 Endeavor da Bruker. O ensaio foi realizado na COAMI do CETEM.

\section{Absorção atômica e análise do pH da água de higienização dos objetos}

O ensaio da água de higienização teve como objetivo coletar toda a forma de impureza que estivesse contida na superfície da escultura e do suporte para que, posteriormente, fosse analisada por absorção atômica. Com o auxílio de uma escova de cerdas macias e de uma pisseta contendo água destilada, foi feita a higienização. Todo o líquido coletado passou por uma filtração a vácuo, que separou o sólido (sujidade) que estava presente no líquido (água de higienização). A sujidade foi avaliada por dois espectrômetros de absorção atômica: Agilent, modelo SpectrAA-55B; e Agilent, modelo SpectrAA-50B, da COAMI do CETEM. O pH da água de higienização foi medido com um pHmetro do modelo digital $\mathrm{DH}-22$, da marca Digimed.

\section{Ensaio colorimétrico}

O ensaio colorimétrico foi realizado para avaliar as características cromáticas das rochas e determinar as variações que elas podem sofrer quando submetidas a processos de alteração física e/ou química. Para tanto, foi utilizado um espectrofotômetro modelo Spectro Guide Sphere Gloss
$T R 220$ da marca $B Y K$. A cor foi determinada segundo o sistema CIE L*a*b*, o qual trabalha de acordo com a norma da Commission Internationale de L'Eclairage - CIE, 1976 (Souza et al., 2008). Os resultados são valores relativos aos eixos $a^{*}, b^{*}$ e L*. O eixo a* indica a variação de cor do verde (-a) ao vermelho (+a); o eixo b*, a variação de cor do azul (-b) ao amarelo (+b); e o eixo $L^{*}$, a variação do claro (100) ao escuro (0) (Gimenez, 2018). Esse ensaio foi realizado também nas amostras de mármores sãos $\mathrm{MB}$ e MC. $\mathrm{O}$ espectrofotômetro utilizado pertence ao Laboratório de Conservação e Alterabilidade de Materiais de Construção (LACON) do CETEM.

\section{Determinação da absorção de água pelas rochas: tubo de Karsten}

A determinação da absorção de água foi realizada por meio da aplicação do "Método do Cachimbo" (ou tubo de Karsten). Esse método mede a quantidade de água absorvida pela superfície do material a ser estudado durante um período específico, com o intuito de avaliar o grau da porosidade e da permeabilidade desse material. $\mathrm{O}$ formato do tubo de Karsten assemelha-se ao de um cachimbo, e sua porção vertical é graduada de 0 a $5 \mathrm{~mL}$. Possui uma borda plana e circular no fundo, a qual foi fixada à superfície com a ajuda de alginato odontológico, um material moldável e selante e que não compromete a estética da superfície pétrea.

O procedimento foi realizado de acordo com o teste $\mathrm{n}^{\circ}$ II.4 RILEM (2006) (Reunion Internationale des Laboratoires D'essais et de Recherches sur les Materiaux et les Constructions). O tubo foi preenchido com água destilada até o nível de referência, o tempo foi marcado e a diminuição na altura da água ao longo do tempo é interpretada como indicação da permeabilidade da rocha. As leituras são feitas aos 5, 10, 15, 30 e 60 minutos. No busto, os primeiros ensaios foram feitos em sua base e em seu topo, e, em seguida, foram selecionados os pontos da testa e do peito. Quanto ao suporte, primeiramente foi feita a colocação do tubo de Karsten em sua lateral e, em seguida, o tubo foi posicionado na parte inferior do suporte.

\section{Ensaio de velocidade de propagação de ondas ultrassônicas}

O ensaio visa medir a velocidade das ondas ultrassônicas (do tipo longitudinal) que percorrem no interior das rochas, podendo assim verificar a existência de descontinuidades no interior. Para a avaliação da escultura, foi usado um medidor de velocidade de pulso ultrassônico PUNDIT (Portable Ultrassonic Non Destructive Digital Indicating Tester), da marca Proceq. Como o suporte possui uma superfície irregular 
(bastante rugosa), não foi possível a realização das medições de velocidade ultrassônica nessa peça. Na Figura 4, estão apresentados os pontos em que foram realizadas as leituras de velocidade ultrassônica na escultura.

Os transdutores foram posicionados pelo arranjo denominado transmissão direta, no qual são dispostos em faces opostas. Esse arranjo é o mais recomendado na determinação da velocidade de propagação de ondas (longitudinais) pelo material, pois, dessa forma, as ondas são recebidas com maior intensidade e precisão (Proceq, 2015). Uma fina camada de gel acoplante foi utilizada nas faces dos transdutores com a função de homogeneizar o contato entre as superfícies em que os transdutores serão posicionados e evitar a perda de sinal (Proceq, 2015).

Esse procedimento foi baseado na norma ABNT NBR $8802 / 19$. Para fins comparativos no resultado de velocidade ultrassônica, foram avaliadas também as duas amostras de mármores sãos utilizados como padrões (MB e MC). $\mathrm{O}$ medidor de velocidade de pulso ultrassônico utilizado pertence ao LACON do CETEM.

\section{Ensaio de dureza}

Para realizar o ensaio de dureza, foi utilizado o durômetro portátil Equotip 550, da marca Proceq. A medição ocorreu a partir do método no qual se posiciona um dispositivo de impacto na superfície do objeto de estudo, aciona-se o botão que libera uma esfera de metal localizada dentro do aparelho, que bate na superfície do objeto de estudo e calcula a dureza superficial do material (Proceq, 2017). Esse ensaio foi realizado também nas amostras de mármores sãos $\mathrm{MB}$ e MC. O durômetro utilizado pertence ao LACON do CETEM.
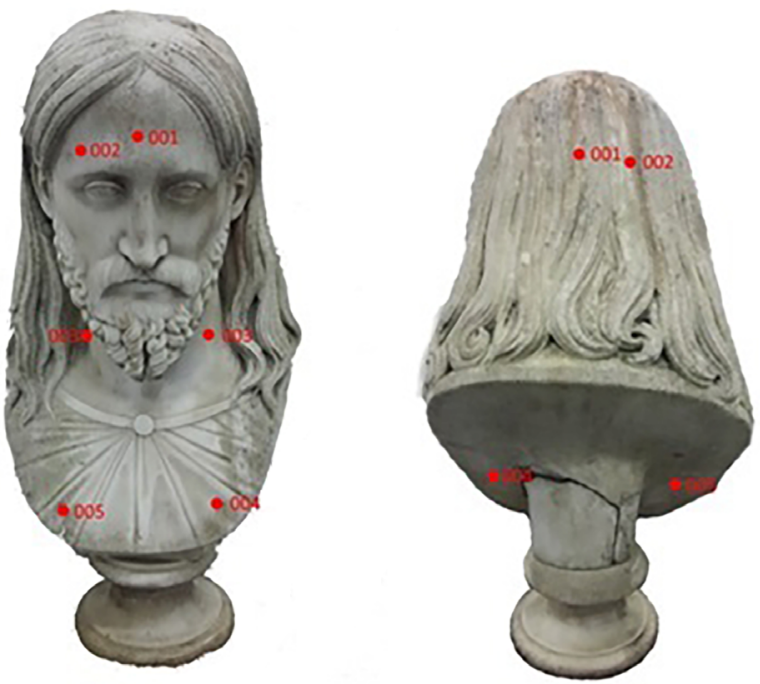

Figura 4. Pontos em que foram realizadas as medições de velocidade ultrassônica na escultura.

\section{RESULTADOS E DISCUSSÃO}

\section{Mapeamento de danos}

O mapeamento de danos realizado na escultura e no suporte pode ser visualizado nas Figuras 5 e 6, respectivamente. Em boa parte da escultura (Figura 5), observam-se alterações

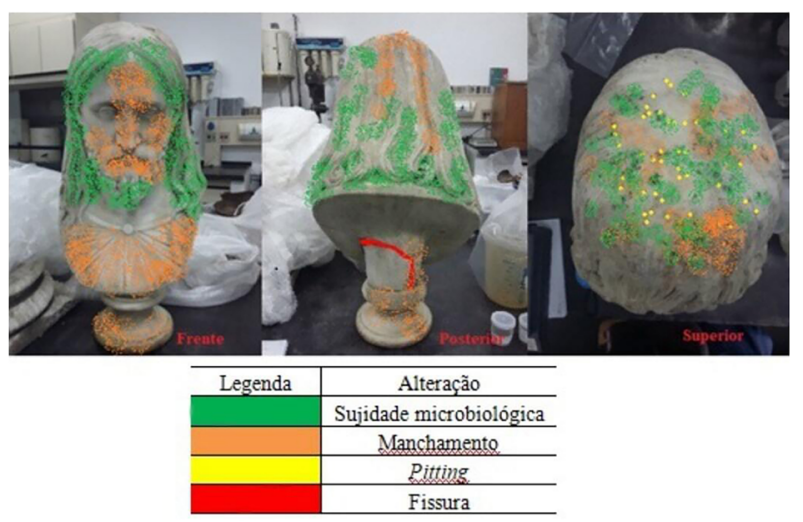

Figura 5. Mapeamento de danos realizado na escultura de Jesus Cristo.

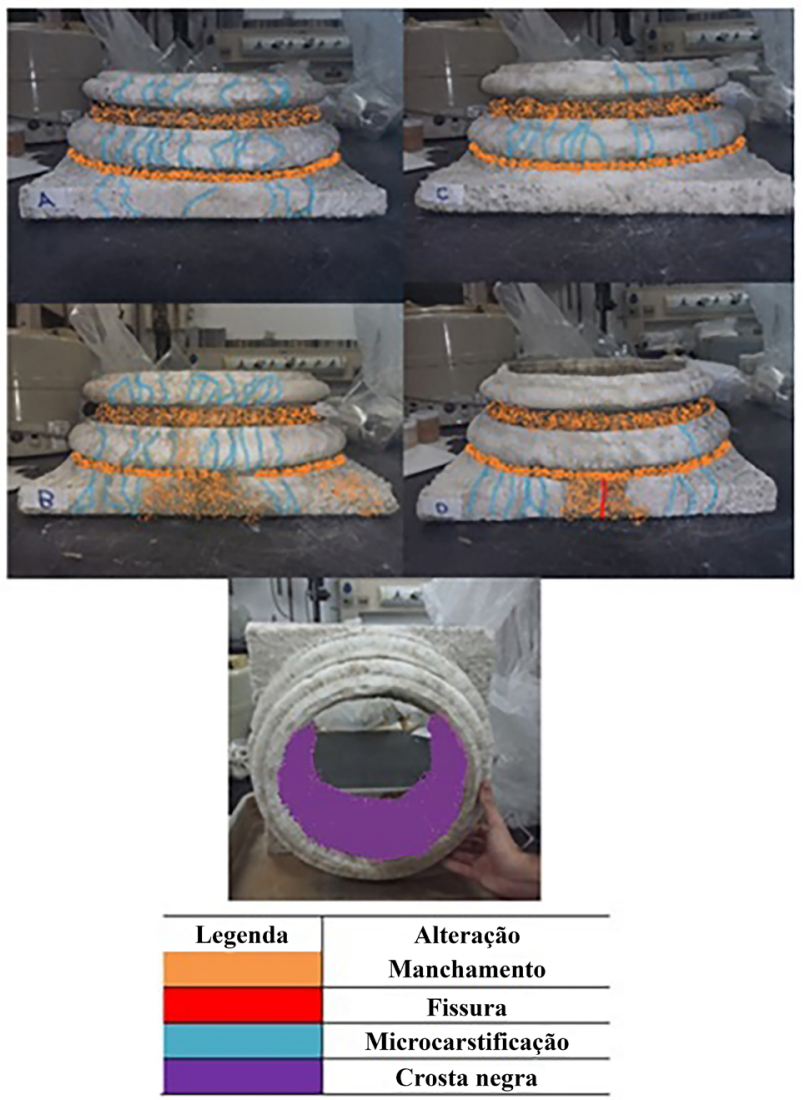

Figura 6. Mapeamento de danos realizados no suporte. 
de sujidade microbiológica (fungos) e manchamentos (alteração cromática). É possível, ainda, observar que na parte posterior do busto há uma fissura. Em seu topo, há a presença de pittings, cavidades de dimensões milimétricas e pouco profundas que não são significantes a ponto de alterar o volume da escultura, e que segundo o Glossário ilustrado das formas de deterioração da pedra (ICOMOS, 2008), são geradas a partir da ação de microrganismos.

Nas reentrâncias das laterais do suporte (Figura 6), observa-se manchamento (alteração cromática), e o lado B é o que apresenta maior alteração cromática. É possível, também, observar que no lado D há uma fissura de extensão centimétrica (aproximadamente $2 \mathrm{~cm}$ ) e espessura milimétrica. O suporte também apresenta, em todas as laterais, a microcarstificação, que é uma estrutura de dissolução que ocorre a partir do escoamento de água em superfície pétrea. No interior da peça, nota-se predominância da crosta negra que, de acordo com o Glossário ilustrado das formas de deterioração da pedra (ICOMOS, 2008), trata-se de uma transformação ocorrida na parte superficial da rocha por acumulação de matéria exógena. As crostas são frequentemente de cores escuras e podem apresentar uma espessura homogênea perceptível a olho nu.

\section{Fluorescência de raios $X$ : caracterização química}

Os resultados obtidos da FRX demonstram que o busto é composto de $49,90 \%$ de óxido de cálcio e possui perda ao fogo de $44,30 \%$, associada à presença de carbonatos, o que constata que essa rocha é formada, principalmente, por calcita, permitindo a classificação da rocha ornamental, aliada à observação macroscópica, como mármore. Já o suporte apresenta teor de $30,90 \%$ de óxido de cálcio, $21,90 \%$ de óxido de enxofre e $22,00 \%$ de perda ao fogo. Isso mostra que a rocha é constituída, principalmente, de sulfato de cálcio, indicando, portanto, ser um alabastro, composto de gipsita.

\section{Difração de raios X: caracterização mineralógica}

Nas Figuras 7 e 8 estão apresentados os difratogramas das amostras referentes à escultura do busto de Jesus Cristo $\mathrm{e}$ à base quadrada, respectivamente. A escultura do busto é composta predominantemente de calcita (denominação mármore), enquanto o suporte é constituído de gipsita (denominação alabastro).

Os resultados do ensaio de caracterização mineralógica (DRX) corroboram com os de caracterização química (FRX),

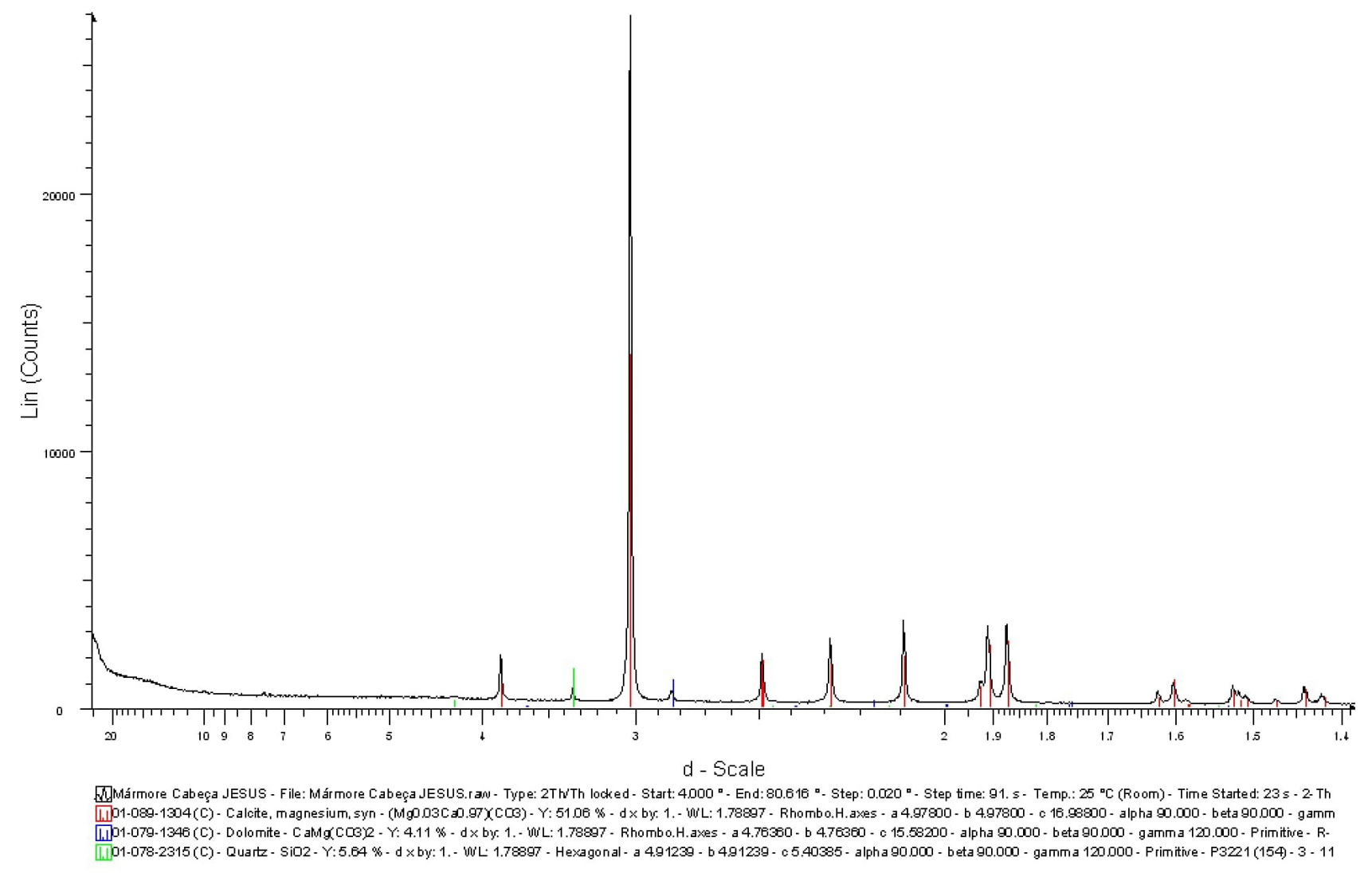

Figura 7. Difratograma da escultura do busto de Jesus. 


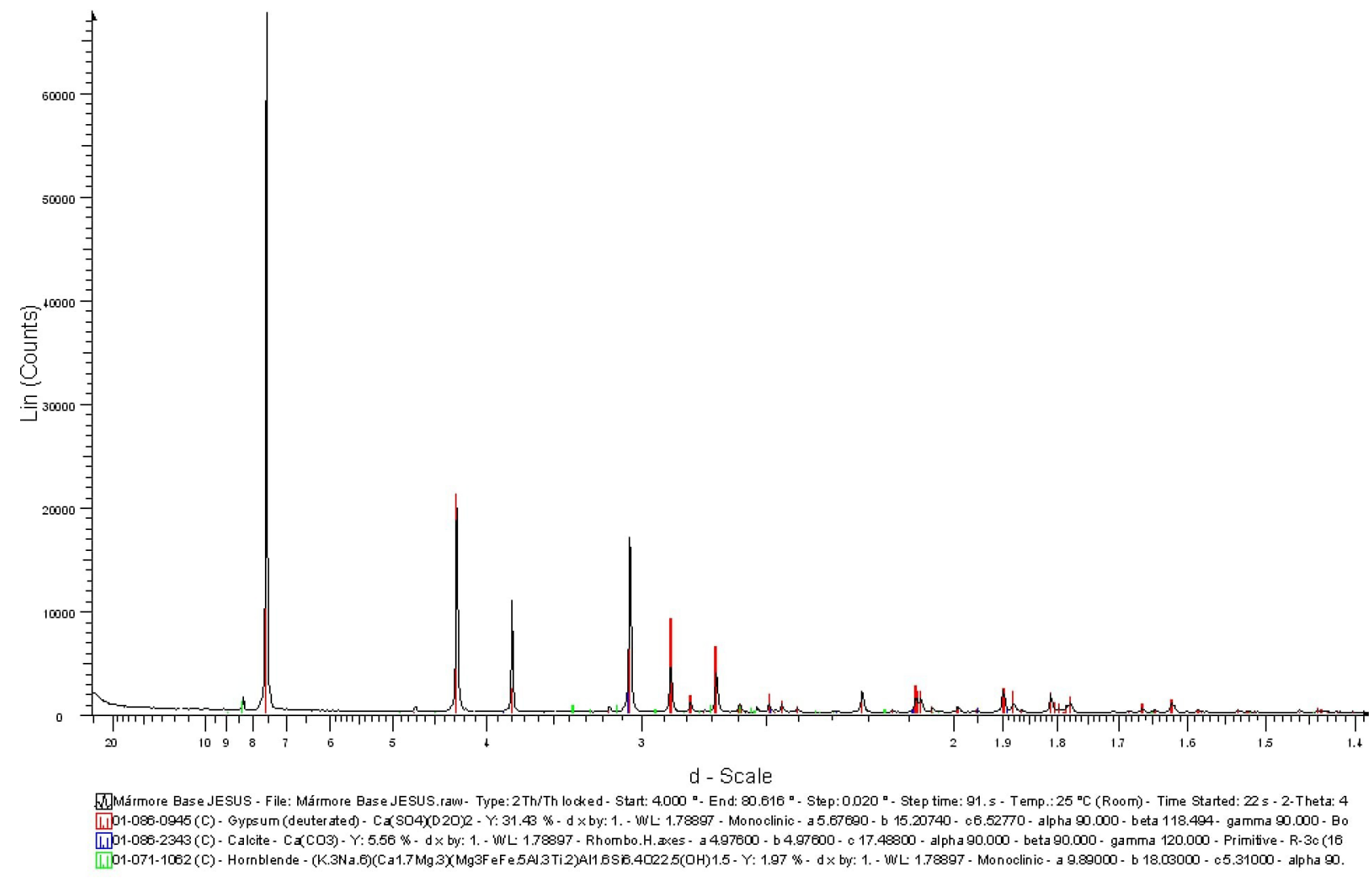

Figura 8. Difratograma do suporte.

em que foi possível certificar que a escultura e o suporte são compostos de materiais diferentes (mármore e alabastro).

\section{Absorção atômica e análise do pH}

Na Tabela 1, pode-se observar os valores dos resultados obtidos da análise química dos íons encontrados na água de higienização, tanto do busto quanto do suporte.

Nesse ensaio, ambos os materiais apresentaram teores significativos de nitrato e, na escultura, de potássio também, possivelmente associado aos excrementos de pássaros que vivem no local. Os teores de cloreto e de sódio são referentes à ação do sal oriundo do spray salino, relacionado à proximidade do mosteiro com o mar da Baía de Guanabara.

As duas peças apresentaram teores significativos de enxofre e cálcio. $\mathrm{O}$ alto teor de cálcio em ambas as peças representa a desintegração das próprias rochas (tanto do mármore quanto do alabastro), e é possivelmente liberado, principalmente, pela ação da chuva ácida, em razão dos poluentes atmosféricos. A presença de enxofre, no caso do suporte, está relacionada à própria desintegração sofrida pela gipsita (sulfato de cálcio hidratado). Na escultura de
Tabela 1. Análise química $\left(\mathrm{mg} \cdot \mathrm{L}^{-1}\right)$ dos íons encontrados na água de higienização.

\begin{tabular}{lcc}
\hline \multirow{2}{*}{ ĺons } & Busto de Jesus Cristo & Suporte \\
\cline { 2 - 3 } & $\left(\mathrm{mg} \cdot \mathrm{L}^{-1}\right)$ & $\left(\mathrm{mg} \cdot \mathrm{L}^{-1}\right)$ \\
\hline $\mathrm{Na}^{+}$ & 8,6 & 3,6 \\
$\mathrm{Al}^{3+}$ & $<0,007$ & $<0,007$ \\
$\mathrm{Ca}^{2+}$ & 33,4 & 369 \\
$\mathrm{Cl}^{-}$ & 13 & 6 \\
$\mathrm{~K}^{+}$ & 11 & 0,41 \\
$\mathrm{Mg}^{+2}$ & 1,2 & 0,05 \\
$\mathrm{~S}^{2-}$ & 150 & 300 \\
$\left(\mathrm{SO}_{4}\right)^{2-}$ & 40 & 1 \\
$\left(\mathrm{NO}_{3}\right)^{-1}$ & 39 & 17 \\
\hline
\end{tabular}

Jesus, pode-se atribuir a presença do enxofre apenas à ação de chuva ácida, resultante de poluentes atmosféricos.

Essa poluição pode ser explicada porque, em frente ao mosteiro, existia um viaduto em que a circulação de carros era 
muito intensa e a emanação de gases dos veículos, caminhões e ônibus contribuía para a deposição de enxofre nas peças. Com o adicional da chuva, que já é ácida pela poluição na cidade do Rio de Janeiro, agravava-se a situação no que tange a acidificação local pela formação de ácidos sulfúrico, sulfuroso e sulfídrico. Consequentemente, o processo de degradação das peças foi acelerado. Esse viaduto foi demolido durante as obras de restauração do centro histórico para as Olimpíadas de 2016.

Neste estudo, foram coletadas quatro amostras de água de higienização do busto de Jesus e da base quadrada para a medição do $\mathrm{pH}$. $\mathrm{O}$ valor médio do $\mathrm{pH}$ obtido para as amostras do busto de Jesus foi de 7,38, que é um pH aproximadamente neutro, enquanto para as amostras do suporte foi de 5,55 , que é um pH ácido. Isso está relacionado com a ação de microrganismos que se acumulam no suporte.

\section{Ensaio colorimétrico}

Nas Tabelas 2 e 3 são apresentados os valores referentes às médias de $\mathrm{L}^{*}, \mathrm{a}^{*} \mathrm{e} \mathrm{b}^{*}$ obtidas a partir do ensaio de colorimetria nas partes frontal, posterior e inferior do busto e nos lados do suporte. Já na Tabela 4, é possível observar os valores referentes às amostras sãs do $\mathrm{MB}$ e do $\mathrm{MC}$.

Com a utilização de um conversor on-line (Nix Sensor, 2021), foi possível associar as cores referentes a cada parte. Tanto a escultura de Jesus quanto o suporte apresentaram cor cinza-escura em seus resultados, enquanto as cores de mármores sãos $\mathrm{MB}$ e $\mathrm{MC}$ geralmente tendem a cinza acromática e branca. Isso mostra que as peças estão com a sua cor alterada.

Tabela 2. Valores referentes às médias de $L^{*}, a^{*} e b^{*} d a$ escultura do busto de Jesus Cristo.

\begin{tabular}{lcccc}
\hline & $\mathbf{L}^{*}$ & $\mathbf{a}^{*}$ & $\mathbf{b}^{*}$ & Cor \\
\hline Parte frontal do busto & 72,32 & 1,14 & 9,9 & \\
Parte posterior do busto & 68,56 & 0,93 & 12,17 & \\
Parte superior do busto & 66,82 & 2,77 & 11,54 & \\
\hline
\end{tabular}

Tabela 3. Valores referentes às médias de $L^{*}, a^{*} e b^{*}$ do suporte.

\begin{tabular}{lcccc}
\hline & $\mathbf{L}^{*}$ & $\mathbf{a}^{\mathbf{*}}$ & $\mathbf{b}^{\mathbf{*}}$ & Cor \\
\hline Lado A & 73,51 & 0,99 & 7,98 & \\
Lado B & 68,07 & 0,68 & 8,9 & \\
Lado C & 70,47 & 0,63 & 7,88 & \\
Lado D & 71,16 & 0,45 & 6,9 & \\
\hline
\end{tabular}

Tabela 4. Valores referentes às médias de $L^{*}, a^{*} e b^{*}$ dos mármores sãos.

\begin{tabular}{ccccc}
\hline & $\mathbf{L}^{*}$ & $\mathbf{a}^{\boldsymbol{*}}$ & $\mathbf{b}^{\boldsymbol{*}}$ & Cor \\
\hline $\mathrm{MB}$ & 80,19 & $-0,85$ & $-1,6$ & \\
MC & 84,85 & $-0,77$ & $-0,96$ & \\
\hline
\end{tabular}

MB: Mármore Brasileiro; MC: Mármore Carrara.

\section{Determinação da absorção de água: tubo de Karsten}

Após 3 horas de ensaio de absorção de água com o tubo de Karsten, não ocorreu nenhum movimento da coluna d'água tanto para a escultura do busto quanto para o suporte. Esse resultado demonstrou que ambas as rochas que compõem a escultura e o suporte apresentam baixa permeabilidade, porque não houve infiltração nas peças e consequente movimento da coluna d'água.

\section{Ensaios de velocidade de propagação de ondas ultrassônicas}

De acordo com os valores obtidos do ensaio de velocidade ultrassônica (Tabela 5), observa-se que os únicos valores que se destacam por estar abaixo dos valores das amostras de $\mathrm{MC}$ e de MB são dos pontos 003 e 005 . Esse resultado aponta que há, possivelmente, uma fratura/descontinuidade na estrutura interna da escultura (nos locais dos pontos 003 e 005). Porém, no geral, sua estrutura interna encontra-se íntegra, visto que nos outros pontos os valores foram próximos aos mármores sãos.

\section{Ensaio de dureza}

De acordo com os valores obtidos das médias de dureza (Tabela 6), observa-se que a parte superior da escultura é

Tabela 5. Valores de velocidade de ondas ultrassônicas.

\begin{tabular}{lc}
\hline Pontos & Velocidade $\left(\mathrm{m} / \mathrm{s}^{-1}\right)$ \\
\hline 1 & 3.694 \\
2 & 3.523 \\
3 & 1.230 \\
4 & 2.608 \\
5 & 2.083 \\
Amostra MC & 2.835 \\
Amostra MB & 3.389 \\
\hline
\end{tabular}

MC: Mármore Carrara; MB: Mármore Brasileiro.

Tabela 6. Valores das médias da dureza.

\begin{tabular}{lc}
\hline & Média da dureza (HLD) \\
\hline MB & 552 \\
MC & 519 \\
Parte frontal do busto & 489,07 \\
Parte posterior do busto & 452,19 \\
Parte superior do busto & 411,2 \\
Lado A do suporte & 188,14 \\
Lado B do suporte & 172,28 \\
Lado C do suporte & 164,57 \\
Lado D do suporte & 201,71 \\
\hline
\end{tabular}

MB: Mármore Brasileiro; MC: Mármore Carrara. 
a que apresenta menor valor de dureza e é, visivelmente, a mais afetada, apresentando mais manchas escuras e pittings. Os valores encontrados no suporte são menores em relação aos das amostras sãs (MB e MC) e aos da escultura.

A estátua apresenta, em geral, uma dureza maior que o suporte, pois se trata de duas rochas diferentes. Porém, apesar de a resistência da estátua ser mais alta do que a do suporte, a estátua apresenta valores de dureza menores do que os das amostras sãs do MB e do MC. Isso indica que tanto a estátua quanto o suporte foram afetados pelo intemperismo.

\section{CONCLUSÕES}

De acordo com os resultados apresentados, é possível concluir que tanto a estátua de Jesus Cristo quanto o seu suporte se alteram por intemperismo, porém com intensidades diferentes. A estátua possivelmente foi esculpida em MC, tendo em vista as características físicas apresentadas pela rocha, sua compatibilidade com a amostra de MC utilizada para comparação e a possibilidade de se tratar do "busto" em mármore mencionado na literatura. Já o suporte foi esculpido em alabastro. Apesar de a estátua se encontrar menos alterada do que o seu suporte, ela também mostrou processo de degradação.

Em razão do valor patrimonial da estátua, e constatando as alterações de ambas as peças, sua exposição foi alterada, saindo do Jardim de Jericó para um ambiente coberto no Mosteiro de São Bento do Rio de Janeiro. Assim, encontramse protegidas da ação direta da chuva e de microrganismos. Essa foi uma sugestão dos autores e que foi acatada pelos profissionais que atuam na conservação do bem tombado.

\section{AGRADECIMENTOS}

Esta pesquisa foi realizada no âmbito do Trabalho de Conclusão de Curso (TCC) da primeira autora no Departamento de Geologia da Universidade Federal do Rio de Janeiro (UFRJ). Os autores agradecem ao Centro de Tecnologia Mineral (CETEM) a infraestrutura, os equipamentos cedidos, as análises realizadas e o financiamento do projeto. Ao professor Emílio Velloso Barroso, do Laboratório de Mecânica e Tecnologia das Rochas (LEMETRO) da UFRJ, o empréstimo do tubo de Karsten utilizado nos ensaios. Ao Instituto do Patrimônio Histórico e Artístico (IPHAN) a permissão de realizar os ensaios. Ao Mosteiro de São Bento o empréstimo das obras para a realização deste trabalho, e ao Monge Pascoal a atenção e a boa vontade ao ceder alguns dados de pesquisa para este estudo. Por fim, à construtora Terreng 0 auxílio financeiro.

\section{REFERÊNCIAS}

Associação Brasileira de Normas Técnicas (ABNT). (2019). NBR 8802/19: Concreto endurecido - Determinação da velocidade de propagação de onda ultrassônica. Rio de Janeiro: ABNT.

Auler, G. (1963). Ferdinand Pettrich 1798-1872. Disponível em: http://www.artedata.com/crml/crml3001.asp?ArtID=18. Acesso em: 6 out. 2020.

Bakolas, A., Biscontin, G., Moropoulou, A., Zendri, E. (1998). Characterization of structural byzantine mortars by thermogravimetric analysis. Thermochimica, 321(1-2), 151-160. https://doi.org/10.1016/S0040-6031(98)00454-7

Frascá, M. H. B. O., Yamamoto, J. K. (2014). Deterioração de rochas graníticas em edificações e monumentos. Investigação por ensaios de alteração acelerada. Revista Brasileira de Geologia de Engenharia e Ambiental, 4(1), 23-32. Disponível em: https://www.abge.org.br/volume-4-numero-1. Acesso em: 11 ago. 2021.

Gimenez, A. M. S. (2018). Suscetibilidade experimental de rochas do patrimônio histórico aos agentes do intemperismo. Tese (Doutorado). São Paulo: Instituto de Geociências, Universidade de São Paulo, 295p. https://doi. org/10.11606/T.44.2018.tde-10072018-152157

Instituto do Patrimônio Histórico e Artístico Nacional (IPHAN). (2019a). Arquivo Noronha Santos. IPHAN. Disponível em: http://portal.iphan.gov.br/ans/. Acesso em: 6 out. 2020.

Instituto do Patrimônio Histórico e Artístico Nacional (IPHAN). (2019b). Bens tombados. IPHAN. Disponível em: http://portal.iphan.gov.br/uploads/ckfinder/arquivos/ BENS\%20TOMBADOS\%20E\%20PROCESSOS\%20 EM\%20ANDAMENTO\%202019\%20MAIO.pdf. Acesso em: 6 out. 2020.

International Council on Monuments and Sites (ICOMOS). (1964). Carta de Veneza. Carta Internacional sobre a Conservação e o Restauro de Monumentos e Sítios. II Congresso Internacional de Arquitetos e Técnicos dos Monumentos Históricos. Veneza: ICOMOS. Disponível em: http://portal.iphan.gov.br/uploads/ckfinder/arquivos/Carta\%20 de\%20Veneza\%201964.pdf. Acesso em: 11 ago. 2021.

International Council on Monuments and Sites (ICOMOS). (2008). Illustrated glossary on stone deterioration patterns. Champigny/ Marne, França: Icomos. Disponível em: https://www.icomos.org/ publications/monuments_and_sites/15/pdf/Monuments_and Sites_15_ISCS_Glossary_Stone.pdf. Acesso em: 11 ago. 2021. 
Nix Sensor. (2021). Disponível em: https://www.nixsensor. com/. Acesso em: 4 ago. 2021.

Özturk, I. (1992). Alkoxysilanes consolidation of stone and earthen building materials. Dissertação de Mestrado. Pensilvânia: Universidade da Pensilvânia. Disponível em: https://core.ac.uk/download/pdf/76382158.pdf. Acesso em: 11 ago. 2021.

Proceq. (2015). Operating Instructions Pundit Lab. Proceq S.A. Disponível em: https://www.proceq.com/uploads/tx_ proceqproductcms/import_data/files/Pundit\%20PL-200_ Operating\%20Instructions_English_high.pdf. Acesso em: 17 ago. 2021.

Proceq. (2017). Operating Instructions Equotip 550. Proceq S.A. Disponível em: https://www.proceq. com/uploads/tx_proceqproductcms/import_data/files/ Equotip_550_Operating_Instructions_English_high. pdf. Acesso em: 11 ago. 2021.

Reunion Internationale des Laboratoires D'essais et de Recherches sur les Materiaux et les Constructions (RILEM). (2006). RILEM II.4: Water absorption tube test.
Ribeiro, R. C., Figueiredo, P., Silva Barbutti, D. (2018). Multi-Analytical Investigation of Stains on Dimension Stones in Master Valentim's Fountain, Brazil. Minerals, 8(10), 465. https://doi.org/10.3390/min8100465

Souza, J. C., Rolim Filho, J. L., Barros, M. L. S. C., Lira, B. B., Silva, S. A., Rieck, F. E. (2008). Análise colorimétrica de rochas ornamentais. III Congresso Brasileiro de Rochas Ornamentaise VI Simpósio de Rochas Ornamentais do Nordeste. Anais. Natal: CETEM, p. 88-96. Disponível em: http://mineralis.cetem.gov. br/handle/cetem/525. Acesso em: 11 ago. 2021.

The Victorian Artists (1997). Frederick August Ferdinand Pettrich. Disponível em: http://www.avictorian.com/Pettrich_ Ferdinand.html. Acesso em: 6 out. 2020.

Vidal, F. V., Azevedo, H. C. A., Castro, N. F. (2013). Introdução. In: Vidal, F. V.; Castro, N. F., Frascá, M. H. B O. Tecnologia de rochas ornamentais: pesquisa, lavra e beneficiamento. Rio de Janeiro: CETEM/MCTI, p. 15-42. Disponível em: http://mineralis. cetem.gov.br/handle/cetem/1960. Acesso em: 11 ago. 2021.

Winkler, E. M. (2013). Stone in architecture: properties, durability. 3. ed. Berlin: Springer -Verlag. https://doi. org/10.1007/978-3-662-10070-7 